\title{
QUEEN'S
UNIVERSITY
BELFAST
}

\section{Responsibility and Well-being: Resource Integration under Responsibilization in Expert Services}

Anderson, L., Spanjol, J., Jeffries, J. G., Ostrom, A. L., Baker, C. N., Bone, S. A., Downey, H., \& Mende, M. (2016). Responsibility and Well-being: Resource Integration under Responsibilization in Expert Services. Journal of Public Policy and Marketing, 35(2), 262-279. https://doi.org/10.1509/jppm.15.140

Published in:

Journal of Public Policy and Marketing

Document Version:

Publisher's PDF, also known as Version of record

Queen's University Belfast - Research Portal:

Link to publication record in Queen's University Belfast Research Portal

Publisher rights

(c) 2016 American Marketing Association.

\section{General rights}

Copyright for the publications made accessible via the Queen's University Belfast Research Portal is retained by the author(s) and / or other copyright owners and it is a condition of accessing these publications that users recognise and abide by the legal requirements associated with these rights.

Take down policy

The Research Portal is Queen's institutional repository that provides access to Queen's research output. Every effort has been made to ensure that content in the Research Portal does not infringe any person's rights, or applicable UK laws. If you discover content in the Research Portal that you believe breaches copyright or violates any law, please contact openaccess@qub.ac.uk. 


\title{
Responsibility and Well-Being: Resource Integration Under Responsibilization in Expert Services
}

\author{
Laurel Anderson, Jelena Spanjol, Josephine Go Jefferies, \\ Amy L. Ostrom, Courtney Nations Baker, Sterling A. Bone, \\ Hilary Downey, Martin Mende, and Justine M. Rapp
}

\begin{abstract}
Responsibilization, or the shift of functions and risks from providers and producers to consumers, has become an increasingly common policy in service systems and marketplaces (e.g., financial, health, governmental). Because responsibilization is often considered synonymous with consumer agency and well-being, the authors take a transformative service research perspective and draw on resource integration literature to investigate whether responsibilization is truly associated with well-being. The authors focus on expert services, for which responsibilization concerns are particularly salient, and question whether this expanding policy is in the public interest. In the process, they develop a conceptualization of resource integration under responsibilization that includes three levels of actors (consumer, provider, and service system), the identification of structural tensions to resource integration, and three categories of resource-integration practices (access, appropriation, and management) necessary to negotiate responsibilization. The findings have important implications for health care providers, public and institutional policy makers, and other service systems, all of which must pay more active attention to the challenges consumers face in negotiating responsibilization and the resulting well-being outcomes.
\end{abstract}

Keywords: responsibilization, resource integration, expert services systems, well-being, transformative service research

Health care providers' and health plans' expectations of patient involvement are rapidly changing. Today, sick or well, people will not benefit from their health care unless they bring to bear considerable knowledge, skills and motivation to participate actively in the care that is available to them (Gruman et al. 2010, p. 350).

C onsumers are increasingly viewed as competent, responsible, and autonomous marketplace agents (Vargo and Lusch 2008; Yngfalk and Yngfalk 2015). The conceptualization of the responsibilized consumer subsumes

Laurel Anderson is Associate Professor of Marketing, Arizona State University (e-mail: laurel.anderson@asu.edu). Jelena Spanjol is Associate Professor of Marketing, University of Illinois at Chicago (e-mail: spanjol@uic.edu). Josephine Go Jefferies is Lecturer in Marketing, Newcastle University (e-mail: jgojefferies35@gmail.com). Amy L. Ostrom is Professor of Marketing, Arizona State University (e-mail: amy.ostrom@asu.edu). Courtney Nations Baker is Assistant Professor of Marketing, University of North Florida (e-mail: courtney. baker@unf.edu). Sterling A. Bone is Associate Professor of Marketing, Utah State University (e-mail: sterling.bone@usu.edu). Hilary Downey is Lecturer in Management, Queens University Belfast (e-mail: hilary.downey@qub.ac. uk). Martin Mende is Associate Professor of Marketing, Florida State University (e-mail: mmende@fsu.edu). Justine M. Rapp is Assistant Professor of Marketing, University of San Diego (e-mail: jrapp@sandiego.edu). Brennan Davis served as associate editor for this article. responsibilities for both personal and larger societal wellbeing (e.g., health, environmental sustainability, poverty), to be fulfilled through consumption choices and behaviors (Giesler and Veresiu 2014). Formally defined as the shift of functions and risks from providers and producers to individual consumers (Harris and White 2013), this neoliberal ${ }^{1}$ responsibilization policy holds consumers accountable for coping with market instabilities and uncertainties by building and deploying necessary capabilities (Brown and Baker 2012; Giesler and Veresiu 2014), which raises issues of public interest and well-being. Responsibilization (as an institutional and market paradigm and policy) is often considered synonymous with consumer agency and well-being. At a broad

\footnotetext{
1Neoliberalism has been discussed across multiple disciplines and investigated by a multitude of researchers. Yet "there exists no agreed-upon definition of neoliberalism" (Goldstein 2012, p. 304). We offer Thorsen's (2010, p. 203) definition of neoliberalism as "a loosely demarcated set of political beliefs which most prominently and prototypically include the conviction that the only legitimate purpose of the state is to safeguard individual liberty." This definition implies that a "virtuous person is one who is able to access the relevant markets and function as a competent actor in these markets. He or she is willing to accept the risks associated with participating in free markets, and to adapt to rapid changes arising from such participation.... Individuals are also seen as being solely responsible for the consequences of the choices and decisions they freely make" (Thorsen 2010, p. 204).
} 
level, our research takes a transformative service research (TSR) perspective and investigates whether responsibilization is truly associated with well-being.

Recent marketing literature has only begun exploring the illusion of agency and power consumers have in the marketplace and the negative consequences of responsibilization policy in creating "hysterical" consumers-overburdened, self-blaming, and stressed (Carrington, Zwick, and Neville 2016). Lacking in this neoliberal view is a recognition of the structural elements in the marketplace that hinder consumer agency (Giesler and Veresiu 2014). By illuminating such structural deficiencies, we explicitly explore policy and marketplace solutions to enhance consumer power and reduce the anxieties and stress accompanying responsibilization. Our core thesis is that the requisite consumer agency (i.e., freedom of choice and ability to exert that choice; Bhattacharjee, Berger, and Menon 2014) and resources for fulfilling the responsibilized consumer role are not attainable without a corresponding marketplace structure. Furthermore, we question whether, even when considering marketplace structure, it is feasible or desirable in terms of public interest and consumer well-being to pursue responsibilization-driven market policy. The clash between a structurally deficient marketplace and the essentiality of consumer agency in fulfilling a responsibilized role is particularly salient (and therefore often debilitating to well-being) in expert service systems. Expert service systems are those with high expertise asymmetry between providers (e.g., physicians, personal finance advisers, insurance agents) and consumers. Expertise asymmetry goes beyond information asymmetry, in which the provider typically has more and better information about the service exchange than the consumer (Singh and Sirdeshmukh 2000). Expert service systems are often networks of related but distinct providers, resulting in complex consumption practices. Access to and utilization of expert and other resources are therefore critical, but routinely unavailable to consumers who need them in order to fulfill the responsibilized role.

The health care service system, in particular, has experienced significant shifts in both market and public policies toward responsibilized consumers, requiring patient engagement (i.e., "ordinary people managing their own health"; Laurance et al. 2014, p. 1627) and advocating patient empowerment, reflected in calls for engaged (i.e., motivated) and enabled (i.e., capable) patients to improve health outcomes (Fumagalli et al. 2015). Despite the positive connotations and aspects reflected in calls for empowered patients to exert their agency by actively choosing treatments and providers, responsibilization essentially forces autonomy onto health care consumers, which in turn "ceases to promote agency" (Davies and Elwyn 2008, p. 135).2

The positive framing of responsibilization co-opts the vocabularies of coproduction. Coproduction reflects value cocreation (Vargo and Lusch 2008) and implies partnering between providers and consumers within the capabilities and preferences of consumers, but, in reality (under

\footnotetext{
2Patient empowerment has been similarly defined in marketing literature as "the set of self-determined behaviors based on patients' individual needs for developing autonomy and competence with their disease" (Prigge et al. 2015, p. 375).
}

responsibilization), it demands mandatory patient activation (Hibbard et al. 2016). Coproduction terminology often appears in public administration and policy literature to convey responsibilization ideas and ideals (e.g., Fotaki 2011). Although such literature appears to refer to the principles of cocreation of value, the philosophical underpinnings of coproduction as presented in the public administration versus the service-dominant logic (SDL) and TSR literature streams are in stark contrast. We use the SDL concept of resource integration (defined as "the incorporation of an actor's resources into the processes of other actors"; Gummesson and Mele 2010, p. 192) as a lens to examine responsibilization and its effects on consumer well-being, and we use SDL vocabulary (i.e., "cocreation") to refer to consumers' participatory activities and value creation in service systems.

Furthermore, given that discourse on responsibilization has co-opted coproduction and cocreation terms (e.g., Needham 2007), but not the spirit of coproduction, we illuminate the structural deficiencies preventing consumer agency in the health care service system. We focus on structure as it represents "the recurrent patterned arrangements which influence or limit the choices and opportunities available" (Barker 2005, p. 448) to resource integrators. Such patterns reflect institutional norms and logics, which can conflict within a service system and create structural tensions (Edvardsson et al. 2014). Our investigation responds to calls for taking into account the "context of context" and structural environment of consumer experiences (Askegaard and Linnet 2011; Giesler and Veresiu 2014). Therefore, in our focus on responsibilization and well-being, we examine the service system as a resource-integration actor (Edvardsson, Skålén, and Tronvoll 2012; Edvardsson et al. 2014).

Consumers negotiating responsibilization differ in how extensively they embrace and are capable of meeting the associated demands (Biebricher 2011). Both meeting and rejecting these demands affect consumers' well-being, reflecting subjective experiences of welfare (Kuykendall, Tay, and Ng 2015) and a continuous balancing of an individual's resources with challenges encountered (Dodge et al. 2012). We find that consumers' negotiation of responsibilization is inherently dynamic and variable, requiring an exposition of the means and strategies employed in this process. Our inquiry follows transformative consumer research principles, as we recognize both the fundamental problem of responsibilization and the complexity and contextuality of consumption experiences (Mick 2006).

By examining well-being cocreation as an enactment of resource integration within the structural elements of expert service systems, we contribute to TSR and policy research in four ways. First, we highlight and address the commingling of coproduction, cocreation, and responsibilization discourses. Second, we respond to recent calls for an investigation of service system structures and examine how they enable or impede consumer agency and resource integration. In the process, we contribute to the conceptualization of responsibilization by identifying critical structural tensions arising at the intersection of responsibilization, cocreation, and policy. Third, we contribute to resource integration and responsibilization literatures by identifying resource-integration practices that a responsibilized consumer must undertake. 
Fourth, we develop a conceptual framework for addressing the identified structural tensions and necessary resourceintegration practices and discuss corresponding policy and market solutions. By doing so, we hope to provide actionable insights for marketing and public policy researchers and practitioners.

We begin by conceptually situating the core construct of responsibilization in relation to commonly adopted vocabularies of coproduction and cocreation. We contrast the underlying assumptions and ideals of coproduction and cocreation under responsibilization with SDL and transformative research. Subsequently, we develop and illustrate a conceptual framework by exploring how providers and consumers in the health care service system experience structural tensions arising from responsibilization. We discuss and conceptually frame emerging policy and market solutions and practices aligned with the structural tensions and resource-integration practices identified. We conclude with broader implications of our theorizing and empirical illustrations for policy and market solutions across other expert service systems.

\section{Conceptual Development: Cocreation, Responsibilization, and Resource Integration in Expert Service Systems}

To tease apart and expose the conflicting logics of cocreation and responsibilization, it is useful not only to compare the underlying assumptions, definitions, and principles of each concept but also to do so through the lens of resource integration, which is central to both. Resource integration (a key concept in SDL; Vargo and Lusch 2008) refers to marketplace actors combining knowledge and skills (among other resources) to create value. Resources can be tangible or intangible, static or dynamic, and actors may own them or have access to them to deploy during resource integration (Edvardsson et al. 2014). While resources by themselves hold no inherent value, they engender potential value that can be (under the right circumstances and within a supportive service system and marketplace structure) integrated across actors in order to generate value (Edvardsson et al. 2014). Actors may have specific intentions for cocreating value from resource integration, but the actual resource integration might not conform to their intentions and might either enhance or destroy the value they seek (Vargo and Lusch 2012). Combined, these arguments suggest that a careful alignment among resources, activities, and processes is needed to accomplish cocreation of value between interacting actors, wherein their expectations, needs, and capabilities are in accord. We view services as "dynamic experiences, co-constructed with customers in accordance with their views. These views may or may not entail active participation but the services are experienced regardless" (Schembri 2006, p. 386). We focus on three actors in our conceptualization: the consumer, the provider, and the service system.

When we view the situation through this actor-centric resource-integration lens (Edvardsson et al. 2014), it becomes clear that responsibilization and coproduction/cocreation espouse different logics. This difference manifests itself in two critical aspects of resource integration germane to the first actor: consumer agency and autonomy and consumer capability.

\section{Responsibilized Consumer Actors}

\section{Consumer Agency and Autonomy}

Consumer agency refers to the presence or absence of choice and the locus of control in consumers' choices (Bhattacharjee, Berger, and Menon 2014). Although choice is generally assumed to be desired and appreciated by consumers, forcing choices under expertise asymmetry (as responsibilization can do) is stressful. In summarizing the downsides of forced choice and autonomy for policy considerations, Botti and Iyengar (2006) point out that both subjective and objective well-being are negatively affected. Making a choice in itself increases perceptions of personal responsibility with the decision and its outcomes (Botti and McGill 2006). Therefore, when individuals are tasked to make choices and conform to the ideals of responsibilization, but are unable to do so because of structural tensions within a service system, the self-blame effect magnifies and induces a vicious cycle. Under responsibilization, resource integration is part of the choice- and decision-making processes consumers engage in as they assess consumption and service options and their corresponding norms. Not succeeding at integrating resources from their personal domain with those from providers and the service system becomes a reflection of consumer deviance, incompetence, and inadequacy under the neoliberal logic of responsibilization (Cova and Dalli 2009; Yngfalk and Yngfalk 2015; Zwick, Bonsu, and Darmody 2008).

In vivid juxtaposition, when resource-integration intentions and behaviors do not yield the desired benefits and outcomes, SDL and TSR conclude that institutional change is necessary because the regulative, normative, and cognitive norms of the service system at large are not aligned with value cocreation efforts among actors (Edvardsson et al. 2014). Rather than viewing ineffective resource integration as a personal failure and societal detriment (as it is viewed under responsibilization; Yngfalk and Yngfalk 2015), cocreation views it as informative to and reflective of institutional logics at play.

Similarly, responsibilization provides the illusion of control, autonomy, and sovereignty over resource integration, whereas cocreation (SDL and TSR) explicitly acknowledges the boundaries of such control. In the context of sustainable consumption, for example, consumers are presented with choices that have been carefully calibrated and assorted by companies (Firat 1996), resulting in consumers operating under an "illusion of choice while both the supposed needs and desires underpinning these choices are constructed, and the choice set is strictly controlled, by marketing managers" (Carrington, Zwick, and Neville 2016, p. 27). That is, under responsibilization, failure to effectively engage in resource integration to create value becomes internalized, illustrating "the illusion of the consumer as a sovereign actor with the power and responsibility to change the system (and the world!)" through resource-integration choices (Carrington, Zwick, and Neville 2016, p. 30).

In contrast, SDL and TSR logics emphasize shared accountability among all resource-integration actors (Edvardsson et al. 2014; Kleinaltenkamp et al. 2012). Wider limitations on choices and, consequently, on resource integration are acknowledged. In the health care system, clinical researchers 
are beginning to recognize the negative effect of forced choices on resource integration: "Where 'autonomous' choice is imposed on an individual, the individual loses the capacity to choose a decisional role and cannot elect to be guided by professional experience" (Davies and Elwyn 2008, p. 322). In discussing the application of SDL to the health care domain, Joiner and Lusch (2016) argue that transferring responsibility to consumers for making resource allocation choices is not consistent with SDL. Rather, with SDL, the focus shifts to the cocreation of consumer self-efficacy, taking constraints into account.

\section{Consumer Capability}

Related to issues of agency and autonomy, capability represents a person's ability or competency to achieve a particular goal or fulfill expectations. Under mandatory autonomy (as engendered in responsibilization), even consumers who are assessed by expert providers as capable of making a wellinformed decision might feel abandoned by the provider and service system (Davies and Elwyn 2008) and, as a result, will likely less effectively integrate resources and cocreate value. This is especially of concern for vulnerable consumers, who often have to confront resource scarcities. Under responsibilization, capability (and the failure to exert it successfully) is perceived as being fully under the control of consumers. In the health care context, a patient's failure to meet perceived expectations of lifestyle and treatment adherence can evoke strong feelings of shame and expressions of inadequacy and self-deprecation in the patient, which hinder effective resource integration during an essential interaction (i.e., doctor-patient consultation; Guassora, Reventlow, and Malterud 2014).

In contrast, SDL and TSR logics treat capability as an essential precondition to resource integration (Haase and Kleinaltenkamp 2011), recognized as both systemic in nature (Edvardsson et al. 2014) and uniquely experienced by individuals. Consumers' capability of being effective resource integrators captures their "proficiency in deploying resources as they engage in value-generating processes" (Hibbert, Winklhofer, and Temerak 2012, p. 248), driven by customer-centric learning activities embedded in and shaped by social and cultural context and values. However, not much is known about how consumers' learning activities are enacted and underpin resource-integration efforts (Hibbert, Winklhofer, and Temerak 2012), particularly in complex and expert service systems. Recent clinical research has suggested that the health care system can be conceptualized as a networked set of learning activities (Faden et al. 2013), encompassing not only all clinical encounters but also various types of research and practices. The recognition that resource-integration capability is not simply an issue of motivation and skill, but rather a laborious and interactive set of processes and activities (Spanjol et al. 2015), acknowledges the complexities of the expert service system and demands a holistic examination of resource integration under responsibilization.

\section{Expert Service Systems: The Case of Health Care}

The complexities of service systems and how they come to bear on resource integration are particularly salient in expert service systems, such as health care. Consumer autonomy and capability issues buttress resource-integration efforts in interactions with the second and third actors, service providers and service system, respectively. Thus, examining responsibilization and how it shapes providers' resource-integration context is informative. How providers view their profession is an active and ongoing debate in health care, partially reflected in the development of and conversation around the Physician Charter (Bryan-Brown and Dracup 2003; Cassel, Hood, and Bauer 2012). The Physician Charter aims to define the fundamental principles of the medical profession-primacy of patient welfare, patient autonomy, and social justice-as a response to market forces and policies that have diminished the ability of expert providers to act in the best interest of their service users:

The medical profession now feels undervalued, threatened, and at times, unable to deliver appropriate care. It wishes greater influence over public policy and a health care system in which its expertise is recognized and used. Along with a loss of influence has come a well-documented loss of trust in the profession.... If the profession is to have significant input into public policy (the social contract), it must be trusted (Brennan et al. 2003, p. 851).

Effective resource integration by providers is thwarted by structural elements of the market system that is grounded in responsibilization and its drive toward market-based solutions aimed at individual consumers solving societal problems (Giesler and Veresiu 2014). Perceptions of the health care system as increasingly profit driven (Bryan-Brown and Dracup 2003) and unaccommodating of professional principles can be observed in the changing definition of good practice as following evidence-based medicine (Greenhalgh et al. 2004). To improve service quality, it becomes necessary to replace reliance on professional opinion with increasingly complex clinical decision making within statistically established, population-based treatment protocols. The market and governments use financial systems to favor certain behaviors by means of incentives that make it clear which treatment guidelines practitioners should follow, thus enforcing these changing norms. Apart from "concierge medicine" (in which physicians take on a small number of patients in order to provide personalized and always accessible health care; Carnahan 2006), service providers have few options to avoid the population-based model advocated by the financial controls of insurance and service payers. Indeed, participating in for-profit concierge medicine services frequently bars a provider from being included in mainstream health care management contracting arrangements (French et al. 2010). Therefore, health care providers must comply with the financial incentives or provide additional care without reimbursement. Nonpayment signals a low market valuation for time spent building trust with patients or attempting to provide more personalized application of medical expertise. As a result, structural tensions in the service system are preventing providers from effectively integrating resources and cocreating valuable and meaningful benefits for their patients and themselves, including even the advocated education of consumers to take on more responsibility:

A disturbing number of physicians reported that they lied to their patients ... or withheld important information. This gap between the ideals espoused in the [Physician] Charter and the 
behavior of actual physicians is frustrating, and we believe it has many causes. First, we have a growing understanding that the systems in which physicians practice tremendously influence their professional behaviors.... Physicians should not constantly have to battle perverse incentives to maintain professional values (Cassel, Hood, and Bauer 2012, p. 291).

The resulting competing institutional logic of physicians' primary principle of patient welfare clashes with that of a yield-focused responsibilization model, inducing a significant structural tension and exemplifying the differences between cocreation and responsibilization (see Appendix). In summary, given the difficulties arising from responsibilization for both consumer and provider efforts toward effective resource integration and the apparent negative well-being outcomes for these actors, our aim is to provide a conceptual framework for understanding (1) where structural tensions arise in the service system and (2) what emerging market and policy solutions might alleviate such tensions to support effective resource integration and value cocreation in expert service systems. We illustrate our conceptual framework with consumer and provider voice data.

\section{Method}

\section{Empirical Context}

We chose the health care service system related to consumers with type 2 diabetes (T2D) as the context for our inquiry. Although responsibilization is evident across many health care and other services, consumers with chronic conditions continuously and indefinitely face demands to live up to a responsibilized consumer role, a situation that more readily exposes the effects on well-being than acute health care service consumption. In addition, chronic conditions serve as an impetus for consumers to interact with many and varied service providers, including medical professionals, insurance providers, food retailers, and exercise vendors. Market policy places the onus of diabetes prevention on the individual with or at risk of developing T2D.

Importantly, the T2D context fits with our focus on expert service systems, which we argue are particularly susceptible to negative well-being consequences due to responsibilization. We are guided by our research questions regarding resource-integration efforts and experiences constrained by structural tensions in the health care service system that have consequences for consumers' well-being. To more fully comprehend the dynamics of resource integration within structural barriers and develop our theoretical framework, we examine not only the consumer voice but also the provider voice. Our approach to using the data collected was guided by thematic interpretation, which we iteratively integrated with theoretical development in concert with the reading of relevant literature. We use the data primarily to illustrate our resulting conceptual framework.

\section{Data Collection and Analysis}

Table 1 presents a summary of the data sources and their use to highlight both consumer and provider voices in relation to the receipt and delivery of T2D health care in the United States. To capture both voices, we used publicly accessible, open discussion forums. Such online communities are part of the service ecosystem, representing a parallel virtual service (Laing, Keeling, and Newholm 2011) and a resource that both providers and consumers deploy and integrate. On the consumer side, we collected data in two online forums (American Diabetes Association [ADA] Community Support Group and DailyStrength [DS] Diabetes Forum), covering postings from January 1, 2012, to July 1, 2015. To assess the provider voice during the same period, we examined three health care professional websites (see Table 1). This combined process resulted in more than 350 web pages of data (i.e., online postings). Other sources (e.g., published articles and editorials in medical journals) provided further insights into the provider domain, and we use the full spectrum of the data to provide illustrative examples for the conceptual framework.

We employed a hermeneutic analysis approach (Thompson 1997) to examine the data and connect it with theory. First, we conducted an intratextual analysis on each of the sites to identify key health issues of concern for people with T2D. Second, we undertook an intertextual analysis to elicit rich detail in identified posting threads. At this stage, the most notable themes as expressed across both consumer and provider forums were gathered for thematic analysis. Finally, we linked our interpretations of the thematic analysis of consumer voices to those of the provider voices for further consideration and comparative analysis. In keeping with our goal of capturing patient experience, in which "language represents the real world" (Oliver, Serovich, and Mason 2005, p. 1274), and in accordance with accepted practice, we do not correct any errors when reporting the postings.

\section{Structural Tensions and Resource Integration: A Conceptual Framework}

Drawing on the integration of theoretical insights from the literature and empirical data examined for this study, we develop a conceptual framework that captures structural tensions of responsibilization (i.e., obstructions to cocreation efforts) in expert service systems, discerns emerging solutions to address such barriers, and identifies resource-integration practices that consumers must accomplish in responsibilization. We first discuss our findings on responsibilizationinduced structural tensions (experienced by both consumers and providers) that hinder effective resource integration; we then offer an exposition of practices (i.e., solutions) for alleviating the identified structural deficiencies and, ultimately, the resource-integration practices that consumers need. Our conceptual framework (see Figure 1) summarizes our theorizing and empirical analysis. It centers on three levels of actors in resource integration (consumer, provider, and system) and incorporates our previous discussion on competing institutional logics within the health care service system, pressures on providers, and agency/autonomy of and capability tensions within consumers.

When consumers are confronted with responsibilization and engage in resource integration in expert service systems, they face the task of acquiring a multitude of highly varied sets of expertise. Yet the structure of the health care service system limits the expertise they are able to gain across domains (e.g., 


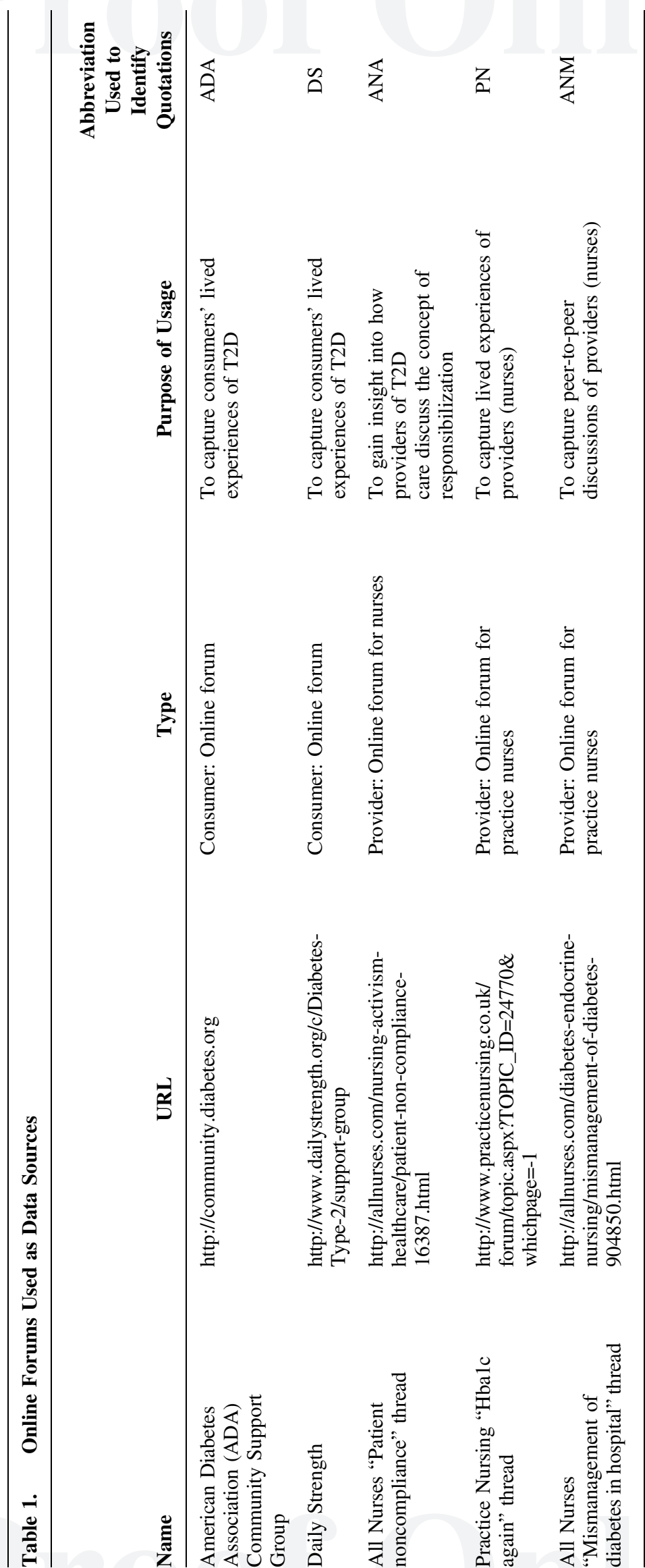




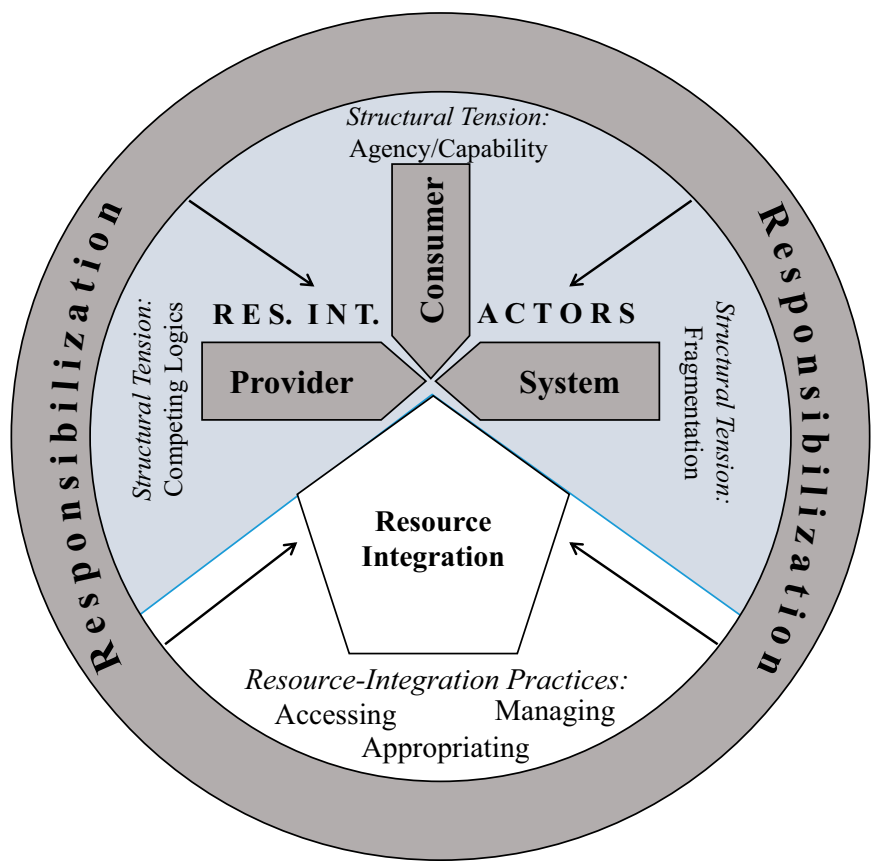

Notes: Res. Int. = resource integration.

expertise with the service system, disease, self-management). In addition, deficiencies in capabilization (i.e., "an infrastructure of products and services that support ... active selfmanagement"; Giesler and Veresiu 2014, p. 843) mean that consumers are left without sufficient support in the form of available product and service offerings from the market to help them gain the expertise required to be effective resource integrators. Overall, these institution-related barriers limit consumer expertise and, thus, consumers' success at resource integration, ultimately leading to the strong potential for reduced well-being. We spotlight structural tensions surrounding three specific resource-integration practices that health care consumers require to successfully integrate resources and enhance well-being: (1) accessing expertise for resource integration, (2) appropriating knowledge for and about resource integration, and (3) managing a fragmented and complex service system for resource integration.

\section{Structural Tension 1: Accessing Expertise for Resource Integration}

The health care service system was built around providing expertise to health care providers and according them with what has become entrenched professional power within this expert-based service system. Not surprising with an expert service system, strong structures are in place to train providers, including medical schools and lengthy residency programs. This expertise allows providers to write prescriptions and control not only medication access but also how readily consumers get access to needed devices and tools, such as diabetes testing strips and lancets. One nurse posted the following grievance in an online forum:

I have to beg to get a doctor to send a refill for diabetic testing strips and lancets. I have been after one doctor for over 2 weeks to send them to my pt [patient], and this pt [patient] tests himself regularly, but they blow him off b/c, I believe, he is Medicaid. How can someone be complaint [compliant] if they don't have the tools to do so?? (ANA2, nurse [see Table 1 for coding of quotation sources])

Even with more formalized training in place, health care providers themselves still struggle to attain the needed expertise and may feel threatened by a more expert patient. According to one nurse,

What you observed ... is a common occurence that threatens the health of many diabetics and even kills some while they are in the hospital. The lack of knowledge many healthcare workers have about diabetes is shockingly inadequate, outdated, and often completely wrong. Diabetes is different than most diseases because patients dose their own medication and also learn how their blood sugar is affected by different variables, so the patients quickly becomes an expert in their own disease. Some physicians and nurses are threatened by that. (ANM1, nurse and diabetic)

Consumers are expected to perform as responsibilized agents, a function that requires an extensive and highly diverse set of expertise, but even when consumers have motivation to learn, no formal educational structures exist to assist them. Access to resources, whether extra time with a health care provider to help enhance consumer expertise or the ability to retrieve (and understand) articles published in medical journals (which are often behind a payment wall), are 
also limited. Ironically, while access to some expert sources is restricted, consumers have a tremendous amount of information available online, including through peer-to-peer forums. The substantial growth in health-related online resources is altering the traditional patient-provider relationship as the patient moves from a passive service recipient toward the role of a partner (Townsend et al. 2015). These forums work to formalize expertise and education, as best they can. A forum participant summarized one of the online health communities as follows:

Just want to welcome you and reiterate what others have already told you: this is the best place to hang out, learn, make friends who understand and are supportive.... There is a real 'brain trust' here (I'm not one of them). To mention just a few: Alan_S, Mollythed, Lecloe, Morris Older, Mary98, and our recently passed dear friend Lizzylou. You should be able to access much of the information she shared over the years on here and in her blog \& website. So, hope to 'see' you in the forum, and welcome to the T2 'family'. (ADA5, consumer)

However, trying to become informed online can prove overwhelming for some consumers. A Google search for "diabetes" returns more than 240 million results, and a search on diabetes forums returns more than 350,000 results. The information available is vast in quantity but difficult to judge in accuracy and source credibility, at times eliciting conflicts in discourses (Carpenter et al. 2016). Many of the online health communities lack input from people with clinical expertise, even though research has shown that such input would be beneficial (Huh and Pratt 2014). This gap has the potential to reduce trustworthy and accurate expertise that consumers can obtain, instead leading to misinformed patients, a major concern for providers (Fox, Ward, and O'Rourke 2005).

Structural tensions not only limit the expertise that can be gained about the disease and treatments but also reduce consumers' ability to gain expertise about self-management of their disease. In the context of diabetes, the ADA defines selfmanagement education as the "ongoing process of facilitating the knowledge, skill and ability necessary for diabetes self-care" (Funnell et al. 2009, p. S87). This expertise is critical for consumers to gain, as is evident to many consumers themselves:

After my initial shock, I told myself two things: the first is that I must educate myself as much as possible on this disease, and secondly I have to do whatever I can do to try to control it.... It is the responsibility of the person with diabetes to take control of their care.... I have made it my goal in life to learn as much as I possibly can about diabetes, how my body reacts to various things, and am constantly "tweaking" my diabetes regime. (DS9, consumer)

Given that no uniform solution exists for many chronic health conditions, especially one that is as complex as diabetes and affected by all types of consumer behavior (e.g., food, exercise) and characteristics (e.g., overall health), it is likely that true understanding can only be gained through consumers' own experimentations with self-management techniques, regiments, and standards. For example, in a post with the subject "Re: This is serious ... sex b4 or after FBS [fasting blood sugar]????" one forum participant advised,

Exercise lowers blood glucose [Smiley emoji]. Delaying testing in the morning can give a higher number, because blood glucose may rise [Sad emoji]. You will only know how they balance out if you try testing before and after. Keep your meter on the nightstand. Be your own science experiment. Reporting the results to the forum is strictly optional [Laughing emoji]. (ADA28, consumer)

Key information about self-experimentation and ways to do it effectively is not routinely available, indicating yet another domain of expertise that consumers must gain with no structure in place to help them do so. Scholars have recognized the power of such self-experimentation attempts (and the sharing of such experiences through online communities) and the learning it generates as reflected in a "wide range of skills and competencies ... to make informed choices, reduce health risks, and increase quality of life" (Zarcadoolas, Pleasant, and Greer 2009, p. 55). Limits to expertise about the disease itself may constrain what types of self-experimentation health care consumers try because their own understanding of behaviors that might affect their health will dictate which factors are the focus of self-experimentation efforts. Fragmentation within the health care system and the multiple and conflicting discourses from providers may also overwhelm consumers as they attempt this process. They may lack the ability to compare and manage the extensive amount of information coming from various sources (medical professionals, peerto-peer forums, pharmaceutical companies, over-the-counter/ direct-to-consumer marketing) to determine what to test in order to judge effects on their well-being. Consumers, especially those with chronic health conditions, routinely seek out peer-to-peer help online (almost 25\% of Internet users in the United States with a chronic illness have tried to connect with individuals with similar health issues online; Fox 2011). Health care consumers often turn to these other "expert" peers to gain knowledge they cannot get from their health care providers, as exemplified in this consumer post:

IF we don't trigger insulin production (not eat), then our bodies eventually begin to break down the stored fat because there is less glucose available for use. (So intermittent fasting helps, too, as far as weight loss AND for both improving insulin sensitivity and decreasing insulin resistance)—-that's what the current Science says. I am hardly a medical expert. However, I have done significant review of the available research and the things I am writing are based on current research done with large populations, over years (not just a few weeks or months), in credible institutions, have been replicated numerous times, and have very good study designs to begin with. I have been utilizing this, myself, with very very good results. I have lost 35 pounds since mid-December. All of my numbers (a1c, cholesterol, triglycerides, resting blood glucose, weight) have gone down markedly. I am sharing because I hope that others will do the research themselves and consider adopting the same type of dietary regimen. Good luck! (DS12, consumer)

These self-made experts reach that status through online research, reading medical publications, self-experimentation, and experience over time. For example, in their analysis of patient versus clinician expertise in the context of breast cancer, Hartzler and Pratt (2011, p. e62) find that although both sources offered information resources, knowledge, perspectives, and action strategies, the knowledge patients provided to other patients was more experiential in nature 
than information provided by clinicians, in that it focused on issues related to "coping with highly personal issues drawn from the context of daily life" and on information "gained not through professional training, but rather through the trial and error of managing the lived experience of illness." Although this type of information is important, it can still be conflicting, and the experiences of one health care consumer may or may not be consistent with those of another.

In addition, although health care consumers could, in theory, experiment with eating and exercising regimens, they may be limited by associated costs (e.g., financial, psychological, time). In terms of the types of drugs and medical devices they might want to experiment with, for example, most consumers are limited by what insurers are willing to reimburse or their providers are willing to prescribe. For consumers without insurance, drug-based self-experimentation is almost impossible, so dietary experiments are more common. As one consumer posted,

I feel like I keep going back and forth, as do my numbers. I have managed 85-120 without medication, if I really focus on what I'm eating.... But more times than I'd like to admit, I keep doing things I shouldn't, and that I know I will regret, just to be able to feel like I have some kind of control. I just don't feel good, at all, and it's bringing me down even more. [Sigh]. I'll work on it... I'm still trying to find someone that might help as far as medication. Having diabetes and not having medical insurance (let alone not being able to afford it) is so difficult. I just want to be healthy, be able to take the medications I need, and just feel better.... There just seems to be so many obstacles. (DS42, consumer)

Vast arrays of products, services, and drugs are available for purchase online that have not been appropriately tested or vetted for consumers' possible use as part of self-experimentation. In a context in which there is a lack of professional support and little input to help health care consumers gauge the success or potential harm that may result from certain self-experimentation choices, circumstances with negative outcomes and reduced well-being are likely to occur.

\section{Structural Tension 2: Appropriating Knowledge for and About Resource Integration}

The many challenges health care consumers confront in their efforts toward responsibilization mean that even if they have access to health information, they will often face situations in which they still lack needed expertise. This is inconsistent with expectations of the health care community, some policy makers, and even, at times, other consumers (e.g., family members, friends, other onlookers) about consumers' ability to utilize knowledge. We call this ability "appropriation" and define it as health care consumers' ability to handle vast amounts of information, turn it into expertise, and effectively deploy those resources in a way that enhances value and their well-being. The health care community and social others tend to believe that because the information is out there, patients should be able to find it, understand it, and implement it. In reality, health management is not so easy, as expressed in the following post:

What sets my hair on fire: When a (nondiabetic) member of the Diabetes Police Swat Team snarkily tells everyone within earshot what I should be eating/not eating, how I could be doing a better job managing my $\mathrm{D}$, etc etc - and this is more irritating because that person doesn't have the (guts) to say these things to my face.
Although rarely possible, (as my alter ego/wicked persona) I'd love to set them straight, tell them exactly where their opinions belong, and wittily mention a few of their faults. I'd be wearing one of my favorite $\mathrm{T}$ shirts that I never get to wear: "I may be fat, but you are ugly, (substitute ignorant); at least I can diet." (ADA5, consumer)

Without the appropriation of knowledge from the experts in the health care system, consumers are less likely to succeed as resource integrators in achieving their desired well-being outcomes. In theory, eating healthfully, exercising, and managing medications in order to live longer seem like obvious steps to take. However, in practice, blood glucose levels can be very volatile, and lifelong habits of poor diet and lack of knowledge about physical fitness, coupled with issues such as poverty (e.g., inability to afford insurance, healthful food, gym memberships) and poor education can make it difficult to manage this disease in real life. Rather than working to understand these contextual nuances, doctors often simply disseminate information and then make patients feel guilty about their lack of compliance. One patient complained,

I really wanna punch my family doctor in the face. He made me an endo [endocrinologist] appointment. I'm not ready for change, sadly, and all this dam endo will tell me is s-I already know and yell at me.... I'm worried the endo is gonna know about my depression. My fam doctor knows thanks to my dumbass son. I think he might tell the endo because if they ask me, which I'm sure they will, I will deny it.... GETTING REALLY SICK OF PEOPLE WHO DONT CARE ABOUT ME, AKA DOCTORS, LECTUREING ME ABOUT MY SUGARS, AND I DON'T GOT TIME TO BE AT DOCTORS ALL THE DAMN TIME. (DS15, consumer)

Faced with a complex service system, differing stakeholder discourses, limited time, information overload and complexity, and a situation characterized by uncertainty and fear, consumers are faced with making many stressful decisions that may not be optimal (Berry and Bendapudi 2007). Ultimately, stress and anxiety may not only lead to but also result from poor decision making when consumers fail or fall short of their duties and obligations engendered in responsibilization.

\section{Structural Tension 3: Managing a Fragmented and Complex Service System for Resource Integration}

While accessing and appropriating expertise are central barriers to effective resource integration, the fragmentation that exists within our third resource-integration actor, the health care service system-especially in the United States (e.g., Stange 2009) — magnifies the problem. The enormity and complexity of the health care service system and the many disconnected providers and other stakeholders make it difficult, for example, for patients to understand who they need to see, when they should see them (e.g., how long they should wait before making an appointment, which provider they should see first), and which processes to follow in order to see them (e.g., when they should get preapproval from the health insurance provider).

Limitations imposed by health insurance policies can also add to confusion when consumers try to find health care providers, make appointments with providers covered by their plans, and distinguish what is covered from what is not (Gorman 2014). Various segments within the population may face added challenges that govern their experience with the 
health care system. Notable examples in the United States are veterans and vulnerable consumers who, despite the Affordable Care Act, remain uninsured. Those who are uninsured sometimes seek alternative routes to health, such as a better diet, given their inability to navigate the system in the intended way. One such consumer posted this experience:

I tried this medication (with side effects) for two weeks.... I couldn't do it. I worked full time, and couldn't afford to have the side effects come out of nowhere. Well, anyway ... it has been a few months now, and I'm not sure what to do at this point. I don't have insurance to get on anything else, I have been able to test my blood sugar and it is usually around 160.: I don't know what to do aside from eat better (which I have been, but not better enough apparently?). I'm suppose to also be on a blood pressure medication also. Can't take that because of no insurance, either. (DS42, consumer)

Without access to the advice of physicians, consumers may turn to community forums that welcome self-made or unofficial "experts." The configuration in which access to expert providers is restricted but unofficial online "experts" are readily available is a frustrating barrier for consumers who strive to manage and improve their own health, as prescribed by the ideals underpinning responsibilization and embraced by many providers. For example, an online forum participant suggested punitive consequences for health care consumers who do not perform to standards of responsibilization:

Maybe it is time for health insurance companies to apply some of the same adjustments to those who truly don't intend to participate in their own well-being, and at the same time reward those who work hard at maintaining or restoring good health. Psycho-babble aside, there is a large contingent of the American population who will soak the system for what they can, and not take any personal responsibility. (ANA1, nurse)

Given a complex network of primary care physicians, specialists, and other health care providers (from dentists to pharmacists), as well as separate testing services, each provider is likely to have a somewhat different view of the patient and not likely to share the same medical perspective, viewpoint, or opinion about treatment specifics. One consumer posted,

My first doctor was so conservative in treating the pre-diabetes that I was just told - go lose weight. That approach did not appeal to me - I wanted some education and guidance.... So, 3 months into the pre-diabetic lifestyle, I decided to try a different doc. Wow, what a HUGE difference. He sat and talked to me for about 20-30 minutes, he listened to my concerns, and he shared a fair amount of info with me, including that he treats pre-diabetes as diabetes (YAY I think) and he treats it aggressively. He wasn't kidding. At the end of the visit I was overwhelmed by the amount of meds he wants me to take. (ADA25, consumer)

Health care providers themselves often have limited knowledge about other providers and services to which consumers also go to for care. That, in addition to short appointment times, means that health care consumers often receive missing, incomplete, or conflicting information as they work to take steps to accomplish their health care goalsranging from not being told to fast for a needed blood test, to being prescribed expensive drugs not covered by insurance without being told about other options, to having different doctors recommend different treatment options and making different estimates of probabilities of various patient outcomes. Beyond these forms of disagreements, discrepancies often exist between service providers' interpretations of standards for care, as seen in a nurse's post:

Our GPs [general practitioners] here started to diagnose pts [patients] on just one HBA1c result $>65 \mathrm{mmols}$ if the patient has no symptoms, I don't think this is right, what do you all think?. My understanding is if patients have not got any symptoms we need two Hbalc $>48 \mathrm{mmols}$ to diagnose but one Hbalc $>48 \mathrm{mmols}$ if they do have symptoms. This job gets more confusing by the day.... There was a patient the other day who the GP had diagnosed diabetes on just one Hbalc with no symptoms, I did a further Hbalc and the second result was less than $48 \mathrm{mmols}$. This confused me and the patient, the GP wasn't happy that I did a further Hbalc as I suppose this made him look silly when he had already given the diagnosis. (PN1, nurse)

Because the system is so fragmented, patients may receive mixed messages about their diseases and treatment. In turn, this creates stress and dilemmas for physicians and nurses, who must choose whether to abide by institutional procedures and rules or to follow their own formal training and (possibly superior) informal experience on the job, as well as their specific knowledge of the patient. Formal systems are touted as wonderful aids to those in need, when in reality, the people carrying out the service might have a different view:

I think that part of the reason that pt's [patients] are non-complaint [non-compliant] is that they lose faith in the medical system. I can see why. Many patients who are on Medicaid are not taken seriously by healthcare practitioners. They are lumped into the category of "Medicaid Leach" and so, their complaints and issues go unheard. (ANA2, nurse)

Tensions due to perceived incompatibility between expertise types and sources can be experienced as cognitive inconsistency (Monge and Contractor 2003), leading consumers to question the legitimacy (Tost 2011) of clinical expertise, especially when compared with their experiential lay expertise (Hartzler and Pratt 2011).

Challenges experienced by health care consumers can amplify those experienced by health care providers. As providers react to pressures to reduce costs and focus on what insurance companies will reimburse, they often reduce time spent with patients, thus limiting the information shared with and the expertise gained by consumers (Rubenstein 2012). Overall, the complexity and fragmentation of the health care system make it challenging for consumers to gain needed expertise involving how to navigate the system successfully, as well as expertise related to their illness (here, T2D). This lack of expertise, in turn, makes it difficult for consumers to orchestrate and deploy resources in the way expected by responsibilization and to bring about the best possible well-being outcomes.

\section{Toward More Effective Resource Integration: Understanding and Matching Emerging Solutions to Structural Tensions}

Our conceptual framework highlights the challenges associated with the structural tensions in and the necessary practices for effective resource integration and well-being (see Figure 1), and it provides a basis for aligning emerging 
solutions and policies to alleviate these tensions. Many innovative solutions (in the market and policy domains) leverage technology as an enabling factor in resource integration (e.g., Singaraju et al. 2016). For example, networked devices and wireless technology provide opportunities for policies like virtual doctor visits and "telehealth" initiatives, as well as for market solutions, such as Apple's CareKit opensource platform, which supports development of health management apps (Versel 2016). However, technology itself does not represent a solution to the structural tensions we identified and the resource-integration practices needed. Rather, people-based solutions are critically important in expert service systems.

In Table 2, we illustrate how emerging solutions are intertwined between public and market policies within the health care field and across all three resource-integration actors (consumers, providers, and service system). Market and government solutions and interventions coexist and are inextricably linked (Stewart 2015) within the institutional field of health care; governmental policies affect the majority of market-based solutions, which in turn influence policy. Our identification of the three requisite resource-integration practices (see Figure 1) provides guidance on the types of solutions that might be most appropriate to support each of these practices and does so for a broad array of market actors, including policy makers (market and public), service organizations, regulators, and other institutions. As the table shows, certain emerging solutions address more than one structural tension, suggesting that policy makers and organizations should consider prioritizing investment in and development of such solutions because they are likely to represent greater opportunity for impact. We also note the importance of aligning different solutions, particularly those that aim to enhance the effectiveness of provider or consumer resource integration.

\section{Conclusions and Implications}

In their Integrated Justice Model, Santos, Laczniak, and FaccaMiess (2015) argue that companies have an ethical responsibility to jointly manage value cocreation (i.e., resource integration) with their customers, especially when consumers fall into disadvantaged segments. Fully endorsing this idea, we propose that contributing to long-term consumer well-being needs to be a core organizational tenet. Our research aims to help service providers and policy makers in their efforts to support more effective cocreation. Specifically, by identifying resource-integration practices that consumers are required to engage in under responsibilization, we provide guidance on the types of solutions that are critically needed.

\section{Policy Implications}

Our research was inspired by the reality that governments and markets increasingly allocate resource-integration responsibilities to consumers (e.g., through coproduction; Mende et al. 2015) and that responsibilization affects resource integration across actors (consumers, providers, and service system). This trend stands in stark contrast to the growing evidence that many consumers struggle to effectively enhance well-being through coproduction and cocreation, despite their motivation and effort. Because of the pervasiveness of responsibilization across service contexts, our work contains several implications that align with both market and public interest.

First, we examine resource integration within the macro context of the health care system. In doing so, we respond to recent calls for research to focus on service systems and their effects on consumer well-being (Anderson et al. 2013). While many studies have examined consumers' service coproduction experiences with one provider, research that broadens the analytical lens to capture the complexities of a service system is limited. We adopt such an expanded perspective and are (to the best of our knowledge) the first to investigate resource integration by contrasting the logics of cocreation (proposed in marketing literature) and responsibilization (proposed in governmentality literature). Our analysis suggests that responsibilization (in juxtaposition to cocreation) creates three significant structural tensions-access, appropriation, and management of expertise and resources - that hinder effective resource integration within expert service systems across actors (i.e., consumers, providers, and service system). By identifying these structural tensions and corresponding resource-integration practices and advancing the conceptualization of responsibilization, we hope to stimulate further research in this domain.

Second, we focus on marketplace and government policies of responsibilization in health care, which mandate that consumers make responsible choices and "manage their lifestyles so as to promote their own health and well-being" (Clarke 2005, p. 451). Notably, health care is not the only service context in which responsibilization occurs; various governments encourage (or urge) their citizens to take responsibility for their diet and weight (Kirkland 2011), physical fitness (Wiest, Andrews, and Giardina 2015), and financial security (Williams 2007). Given the ubiquity of responsibilization, our research is a rather conservative assessment of its effects on well-being because we investigate only one sector. Responsibilization is likely to have additive (if not multiplicative) effects across ofteninterrelated service sectors (e.g., health care and financial services). In other words, the effects of responsibilization on consumer well-being might be more profound and severe than our findings imply, a concerning notion that deserves more scholarly attention.

In addition to the just-mentioned public interest and marketplace implications, responsibilization might have consequences that were unintended by policy makers and the marketplace. For example, popular media and medical literature increasingly blame parents for childhood obesity (e.g., Lupton 2011). That is, they portray parental food choices as free decisions, while discounting the fact that, at last partially, changes in the food industry (e.g., higher calorie levels, larger portion sizes, marketing efforts) are also major drivers of (childhood) obesity. More generally, the neoliberal lens of responsibilization suggests that "responsible citizens make reasonable choices - and therefore 'bad choices' result from the willfulness of irresponsible people, rather than the structural distribution of resources, capacities and opportunities" (Clarke 2005, p. 451). We believe that scholars at the intersection of marketing and public policy are uniquely qualified to contribute to a deeper understanding of 


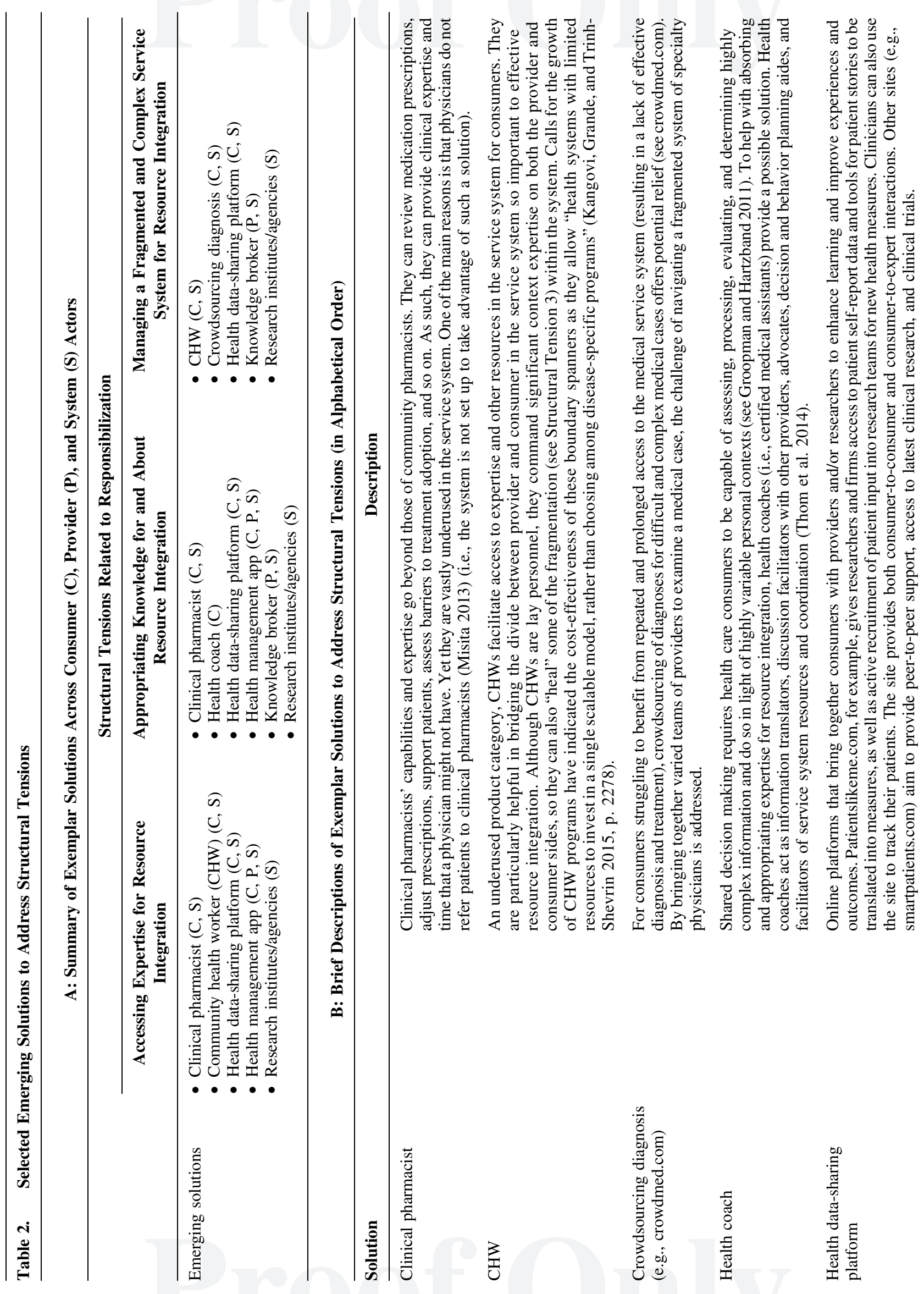




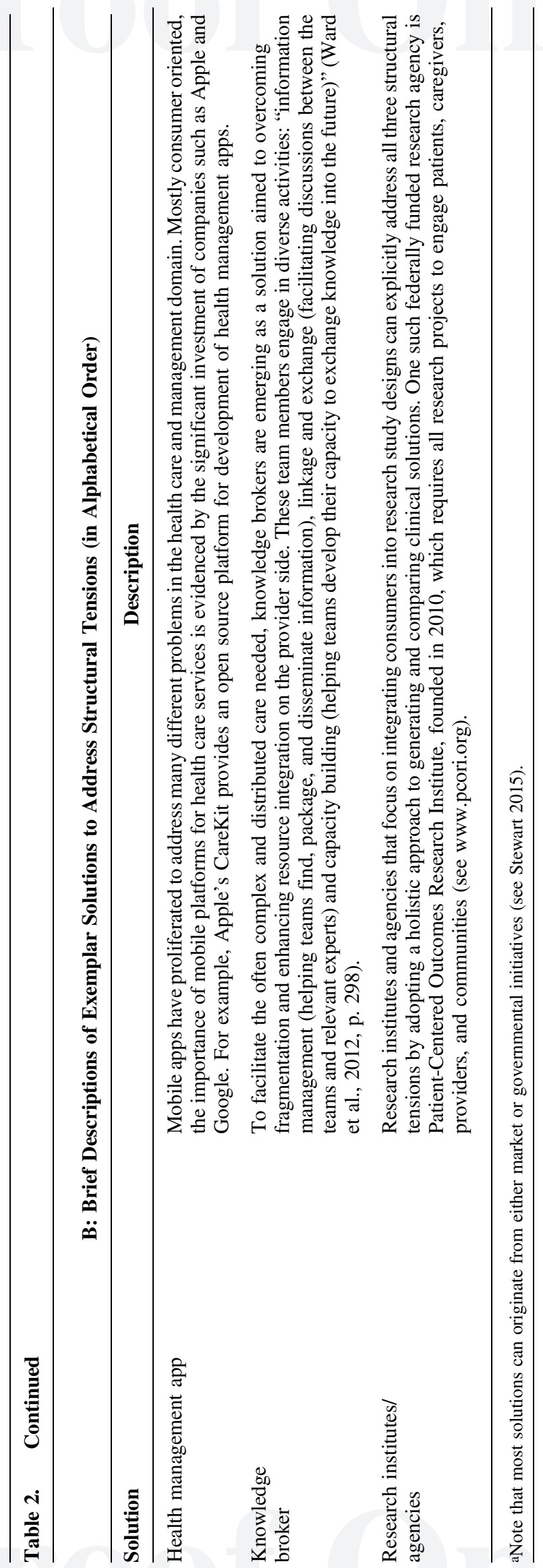


(dis)advantages linked to the idea of responsibilization, particularly relative to alternative paradigms in marketing (e.g., SDL's coproduction). Especially because responsibilization (1) has received scant scholarly attention in service literature and (2) is an increasingly omnipresent phenomenon in consumers' lives, it needs to be investigated by consumer researchers.

Third, we recommend that service organizations, potentially in collaboration with or supported by policy makers, segment consumers on the basis of their service (system) literacy and customize the coproduction experience. Because consumer autonomy/access and capability are cornerstones of successful resource integration, modern technologies, such as the concept of gamification (Maynard et al. 2012), can be powerful tools. Service systems could create "coproduction games" to boost consumer autonomy and capability in a customized manner (e.g., games could be played on smartphones and self-adjust to the focal player's abilities). ${ }^{3}$ Such coproduction games would not only be accessible at all times but would also serve as a way to provide encouragement to consumers. From an organizational perspective, coproduction games are cost-efficient and allow service systems to (potentially) share data on consumers in order to improve their coproduction experience. Finally, such technology would also help build credibility through certifications that players could earn (recall the lack of credibility in peer-to-peer networks). For example, Jane McGonigal's SuperBetter game (www. superbetter.com) has garnered widespread attention as a vehicle for alleviating anxiety and depression and enhancing personal resilience. Public interest implications might include the provision of research grants toward gamification solutions for effective resource integration.

These aspects suggest that service organizations in the twentyfirst century need to consider new forms of interorganizational collaboration (e.g., between for-profit and nonprofit organizations, policy makers, and consumer/peer-to-peer networks). Such collaborations might result in the creation of new certifications, such as expert patient designations and courses that include regulated certification courses and programs.

Finally, policy makers might examine the incentives that motivate resource-integration actors (i.e., consumers, providers, and service system). One way to align the various incentives in the long run would be for policies to incorporate a focus on consumer well-being into the expert-generating systems - that is, into the educational systems that produce service professionals. For example, educational curricula (e.g., in medical and business schools) could include courses on consumer well-being and responsibilization, so that future service professionals and managers would be trained-from the onset of their careers - to attend to well-being at the consumer, provider, and more general service system levels.

\footnotetext{
${ }^{3}$ For example, the Doorways to Dreams Fund (which focuses on vulnerable, low-to-moderate-income households) uses the video game Financial Entertainment to build the personal financial management capability of its clients; initial evidence suggests that this game successfully engages consumers, helps cultivate financial literacy, and positively affects financial decisions (Maynard et al. 2012). Such games, though not applicable to every service and consumer, could form the basis for corresponding coproduction games in financial services, health care, and other well-being settings.
}

\section{Limitations and Further Research}

One limitation of our work, although it is based on extensive theorizing and drawing on observational data, is its empirical focus on a single industry. While T2D in particular and the health care system in general allow a rich examination of the conceptual issues surrounding responsibilization, resource integration, and well-being, other service domains are equally important to investigate. As such, the field is rife with opportunities for understanding the scope and depth of the arguments we present herein.

Across industries within the general service context, consumers, providers, organizations, and service systems are faced with both the expectations of and lack of clarity surrounding responsibilization in the service script (e.g., retirement and financial services, higher education). The cornerstones of consumer agency, autonomy, and capability can guide future research efforts. Naturally, these concepts relate to research on consumer expertise, defined as the ability to perform consumption-related tasks (Alba and Hutchinson 2000), and research on various forms of consumer literacy (e.g., financial, media, medical literacy; e.g., Lusardi and Mitchell 2008; Peerson and Saunders 2009). However, investigating resource integration within the context of service systems also requires a more macro perspective, which is (among other things) reflected in new constructs. For example, medical literacy has been conceptualized as a consumer's ability to perform reading and numerical tasks required in a health care environment (Baker 2006; Peerson and Saunders 2009). It is easy to imagine a consumer with high levels of this medical literacy who still struggles with successful resource integration because of the system-related tensions identified in our research. In other words, most of the constructs that services and marketing scholars frequently examine do not capture the full scope of consumers' experiences, resulting in considerable conceptual voids in extant theories. Therefore, new constructs (and corresponding measures and/or indicators) are required. Examples include consumer service system literacy or, conversely, system-derived consumer fatalism, coproduction overload, and consumer burnout due to resource-integration experiences with service systems (analogously, system-level constructs on the service provider's side are equally relevant). Incorporating these novel facets into existing conceptual models of service coproduction would be a major step forward.

Future work should also empirically evaluate strategic solutions to navigating the complexities of critical service systems, as well as measure consumer service (system) literacy for the ultimate well-being of all involved stakeholders. In both the health care industry and other service sectors, the motives of policy makers, business entities, and consumer advocates must align for the collective benefit and overall health of the service system. Selected strategies must be observed holistically to understand the benefits and detriments that are rooted in all opportunities. Policy researchers should continue to evaluate how proposed solutions to stakeholder tensions can help alleviate the burden of responsibilization. Doing so would involve fostering an environment of collaboration, developing shared knowledge, and facilitating resource integration across relationships, with the goal of optimal service delivery. 


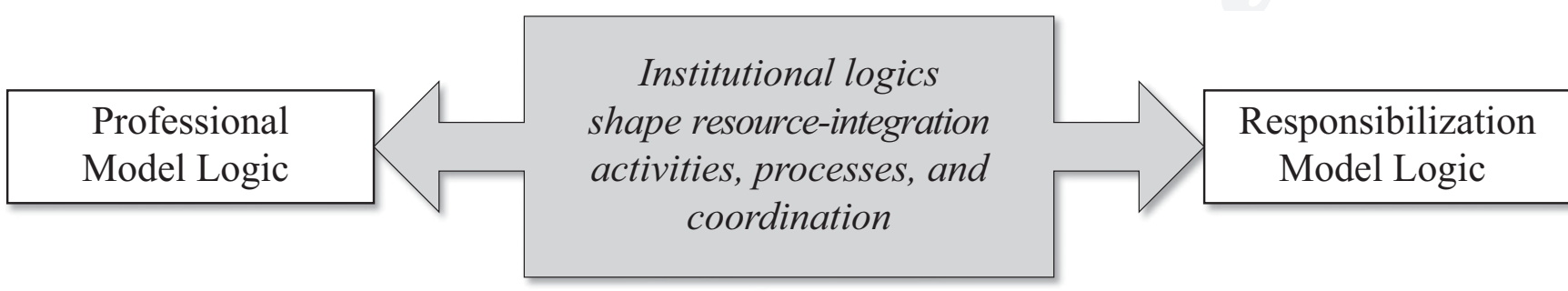

Patient welfare principle $\longleftarrow$ Central professional principle $\longrightarrow$ Patient autonomy principle ...individual patient needs $\longleftarrow$ Professional expertise focused on... $\longrightarrow$ ...population- and evidence-based care

...restricted by ethical considerations

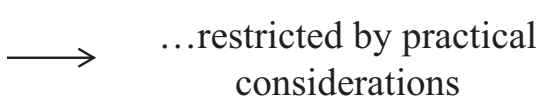
considerations

...viewed as interfering in professional-patient trust relationship

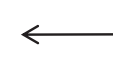

$$
\begin{aligned}
& \text { Expertise redistribution to } \\
& \text { nonprofessionals... }
\end{aligned}
$$

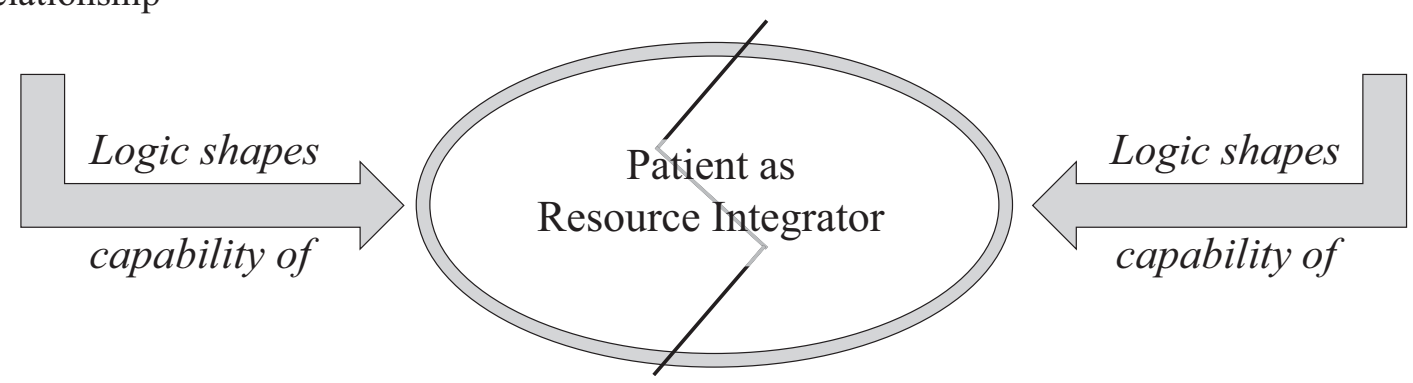

\section{References}

Alba, Joseph W. and J. Wesley Hutchinson (2000), "Knowledge Calibration: What Consumers Know and What They Think They Know," Journal of Consumer Research, 27 (2), 123-56.

Anderson, Laurel, Amy L. Ostrom, Canan Corus, Raymond P. Fisk, Andrew S. Gallan, Mario Giraldo, et al. (2013), "Transformative Service Research: An Agenda for the Future,"Journal of Business Research, 66 (8), 1203-10.

Askegaard, Søren and Jeppe Trolle Linnet (2011), "Towards an Epistemology of Consumer Culture Theory Phenomenology and the Context of Context," Marketing Theory, 11 (4), 381-404.

Baker, David W. (2006), "The Meaning and the Measure of Health Literacy,” Journal of General Internal Medicine, 21 (8), 878-83.

Barker, Chris (2005), Cultural Studies: Theory and Practice. London: Sage Publications.

Berry, Leonard L. and Neeli Bendapudi (2007), "Health Care: A Fertile Field for Service Research," Journal of Service Research, $10(2), 111-22$.

Bhattacharjee, Amit, Jonah Berger, and Geeta Menon (2014), "When Identity Marketing Backfires: Consumer Agency in Identity Expression," Journal of Consumer Research, 41 (2), 294-309.
Biebricher, Thomas (2011), “(Ir-)responsibilization, Genetics, and Neuroscience," European Journal of Social Theory, 14 (4), 469-88.

Botti, Simona and Sheena S. Iyengar (2006), "The Dark Side of Choice: When Choice Impairs Social Welfare," Journal of Public Policy \& Marketing, 25 (Spring), 24-38.

_ and Ann L. McGill (2006), "When Choosing Is Not Deciding: The Effect of Perceived Responsibility on Satisfaction," Journal of Consumer Research, 33 (2), 211-19.

Brennan, Troyen A., Christopher J. Lyons, Richard L. Cruess, and Sylvia L. Cruess (2003), "Charter on Medical Professionalism: Putting the Charter into Practice," Annals of Internal Medicine, 138 (10), 851-55.

Brown, Brian J. and Sally Baker (2012), Responsible Citizens: Individuals, Health, and Policy Under Neoliberalism. London: Anthem Press.

Bryan-Brown, Christopher W. and Kathleen Dracup (2003), "Professionalism," American Journal of Critical Care, 12 (5), 394-96.

Carnahan, Sandra J. (2006), "Law, Medicine, and Wealth: Does Concierge Medicine Promote Health Care Choices, or Is It a Barrier to Access?" Stanford Law \& Policy Review, 17 (1), 121-63.

Carpenter, Delesha M., Lorie L. Geryk, Annie T. Chen, Rebekah H. Nagler, Nathan F. Dieckmann, and Paul K.J. Han (2016), 
"Conflicting Health Information: A Critical Research Need," Health Expectations, forthcoming [DOI: 10.1111/hex.12438].

Carrington, Michal Jemma, Detlev Zwick, and Benjamin Neville (2016), "The Ideology of the Ethical Consumption Gap," Marketing Theory, 16 (1), 21-38.

Cassel, Christine K., Virginia Hood, and Werner Bauer (2012), "A Physician Charter: The 10th Anniversary," Annals of Internal Medicine, 157 (4), 290-91.

Clarke, John (2005), "New Labour's Citizens: Activated, Empowered, Responsibilized, Abandoned?" Critical Social Policy, 25 (4), 447-63.

Cova, Bernard and Daniele Dalli (2009), "Working Consumers: The Next Step in Marketing Theory?" Marketing Theory, 9 (3), 315-39.

Davies, Myfanwy and Glyn Elwyn (2008), “Advocating Mandatory Patient 'Autonomy' in Healthcare: Adverse Reactions and Side Effects," Health Care Analysis, 16 (4), 315-28.

Dodge, Rachel, Annette P. Daly, Jan Huyton, and Lalage D. Sanders (2012), "The Challenge of Defining Wellbeing," International Journal of Wellbeing, 2 (3), [available at http:// www.internationaljournalofwellbeing.org/index.php/ijow/article/ view/89].

Edvardsson, Bo, Michael Kleinaltenkamp, Bård Tronvoll, Patricia McHugh, and Charlotta Windahl (2014), "Institutional Logics Matter When Coordinating Resource Integration," Marketing Theory, 14 (3), 291-309.

— , Per Skålén, and Bård Tronvoll (2012), "Service Systems as a Foundation for Resource Integration and Value Co-Creation," Review of Marketing Research, 9 (2), 79-126.

Faden, Ruth R., Nancy E. Kass, Steven N. Goodman, Peter Pronovost, Sean Tunis, and Tom L. Beauchamp (2013), "An Ethics Framework for a Learning Health Care System: A Departure from Traditional Research Ethics and Clinical Ethics," Hastings Center Report, 43 (S1), S16-27.

Firat, A. Fuat (1996), "The Unmanageable Consumer: Contemporary Consumption and Its Fragmentations," Journal of Consumer Policy, 19 (3), 393-96.

Fotaki, Marianna (2011), "Towards Developing New Partnerships in Public Services: Users as Consumers, Citizens, and/or CoProducers in Health and Social Care in England and Sweden," Public Administration, 89 (3), 933-55.

Fox, Nicholas J., Katie J. Ward, and Alan J. O'Rourke (2005), “The 'Expert Patient': Empowerment or Medical Dominance? The Case of Weight Loss, Pharmaceutical Drugs, and the Internet," Social Science \& Medicine, 60 (6), 1299-309.

Fox, Susannah (2011), "Peer-to-Peer Health Care," report, Pew Research Center (February 28), [available at http://www.pewinternet.org/2011/ 02/28/peer-to-peer-health-care-2/].

French, Michael T., Jenny F. Homer, Shay Klevay, Edward Goldman, Steven G . Ullmann, and Barbara E. Kahn (2010), "Is the United States Ready to Embrace Concierge Medicine?" Population Health Management, 13 (4), 177-82.

Fumagalli, Lia Paola, Giovanni Radaelli, Emanuele Lettieri, and Cristina Masella (2015), "Patient Empowerment and Its Neighbours: Clarifying the Boundaries and Their Mutual Relationships," Health Policy (Amsterdam), 119 (3), 384-94.

Funnell, Martha M., Tammy L. Brown, Belinda P. Childs, Linda B. Haas, Gwen M. Hosey, Brian Jensen, et al. (2009), "National Standards for Diabetes Self-Management Education," Diabetes Care, 32 (Supplement 1), S87-94.
Giesler, Markus and Ela Veresiu (2014), "Creating the Responsible Consumer: Moralistic Governance Regimes and Consumer Subjectivity," Journal of Consumer Research, 41 (3), 840-57.

Goldstein, Daniel M. (2012), "Decolonialising 'Actually Existing Neoliberalism," Social Anthropology, 20 (3), 304-09.

Gorman, Anna (2014), "Many New Patients Overwhelmed by Health Care Jargon," The Rundown (blog), (June 16), PBS Newshour, [available at http://www.pbs.org/newshour/rundown/ many-new-patients-overwhelmed-health-care-jargon/].

Greenhalgh, T., G. Robert, S.P. Bate, O. Kyriakidou, and F. Macfarlane (2004), "How to Spread Good Ideas: A Systematic Review of the Literature on Diffusion, Dissemination, and Sustainability of Innovations in Health Service Delivery and Organisation," report, National Co-ordinating Centre for NHS Service Delivery and Organisation, [available at http://www.netscc.ac.uk/hsdr/files/project/ SDO_FR_08-1201-038_V01.pdf].

Groopman, Jerome and Pamela Hartzband (2011), Your Medical Mind: How to Decide What Is Right for You. New York: Penguin.

Gruman, Jessie, Margaret Holmes Rovner, Molly E. French, Dorothy Jeffress, Shoshanna Sofaer, Dale Shaller, et al. (2010), "From Patient Education to Patient Engagement: Implications for the Field of Patient Education," Patient Education and Counseling, 78 (3), 350-56.

Guassora, Ann Dorrit, Susanne Reventlow, and Kirsti Malterud (2014), "Shame, Honor, and Responsibility in Clinical Dialog About Lifestyle Issues: A Qualitative Study About Patients' Presentations of Self," Patient Education and Counseling, 97 (2), 195-99.

Gummesson, Evert and Cristina Mele (2010), "Marketing as Value Co-Creation Through Network Interaction and Resource Integration," Journal of Business Market Management, 4 (4), 181-98.

Haase, Michaela and Michael Kleinaltenkamp (2011), "Property Rights Design and Market Process: Implications for Market Theory, Marketing Theory, and S-D Logic," Journal of Macromarketing, 31 (2), 148-59.

Harris, John and Vicky White (2013), A Dictionary of Social Work and Social Care. Oxford, UK: Oxford University Press.

Hartzler, Andrea and Wanda Pratt (2011), "Managing the Personal Side of Health: How Patient Expertise Differs from the Expertise of Clinicians," Journal of Medical Internet Research, 13 (3), e62.

Hibbard, Judith H., Jessica Greene, Rebecca Sacks, Valerie Overton, and Carmen D. Parrotta (2016), “Adding a Measure of Patient Self-Management Capability to Risk Assessment Can Improve Prediction of High Costs," Health Affairs, 35 (3), 489-94.

Hibbert, Sally, Heidi Winklhofer, and Mohamed Sobhy Temerak (2012), "Customers as Resource Integrators: Toward a Model of Customer Learning," Journal of Service Research, 15 (3), 247-61.

Huh, Jina and Wanda Pratt (2014), "Weaving Clinical Expertise in Online Health Communities," in Proceedings of the SIGCHI Conference on Human Factors in Computing Systems, Matt Jones and Philippe Palanque, eds. New York: Association for Computing Machinery, 1355-64.

Joiner, Keith and Robert Lusch (2016), "Evolving to a New ServiceDominant Logic for Health Care," Innovation and Entrepreneurship in Health, 3 (3), 25-33.

Kangovi, Shreya, David Grande, and Chau Trinh-Shevrin (2015), "From Rhetoric to Reality: Community Health Workers in 
Post-Reform US Health Care," New England Journal of Medicine, 372 (24), 2277-79.

Kirkland, Anna (2011), "The Environmental Account of Obesity: A Case for Feminist Skepticism," Signs, 36 (2), 463-85.

Kleinaltenkamp, Michael, Roderick J. Brodie, Pennie Frow, Tim Hughes, Linda D. Peters, and Herbert Woratschek (2012), "Resource Integration," Marketing Theory, 12 (2), 201-05.

Kuykendall, Lauren, Louis Tay, and Vincent Ng (2015), "Leisure Engagement and Subjective Well-Being: A Meta-Analysis," Psychological Bulletin, 141 (2), 364-403.

Laing, Angus, Debbie Keeling, and Terry Newholm (2011), "Virtual Communities Come of Age: Parallel Service, Value, and Propositions Offered in Communal Online Space," Journal of Marketing Management, 27 (3/4), 291-315.

Laurance, Jeremy, Sarah Henderson, Peter J. Howitt, Mariam Matar, Hanan Al Kuwari, Susan Edgman-Levitan, et al. (2014), "Patient Engagement: Four Case Studies That Highlight the Potential for Improved Health Outcomes and Reduced Costs," Health Affairs, 33 (9), 1627-34.

Lupton, D. (2011), “'The Best Thing for the Baby': Mothers' Concepts and Experiences Related to Promoting Their Infants' Health and Development," Health Risk \& Society, 13 (7), 637-51.

Lusardi, Annamaria and Olivia S. Mitchell (2008), "Planning and Financial Literacy: How Do Women Fare?" Working Paper No. 13750, National Bureau of Economic Research.

Maynard, Nicholas W., Preeti Mehta, Jonas Parker, and Jeffrey Steinberg (2012), "Can Games Build Financial Capability?" working paper, RAND Corporation, [available at http:// www.rand.org/pubs/working_papers/WR963.html].

Mende, Martin, Maura L. Scott, Mary Jo Bitner, and Amy L. Ostrom (2015), "Activating Consumers for Better Service Coproduction Outcomes Through Eustress: The Interplay of Firm-Assigned Workload, Service Literacy, and Organizational Support," Journal of Public Policy \& Marketing, forthcoming (published electronically December 11), [DOI: 10.1509/jppm. 14.099].

Mick, David G. (2006), "Meaning and Mattering Through Transformative Consumer Research," in Advances in Consumer Research, Vol. 33, Connie Pechmann and Linda Price, eds. Duluth, MN: Association for Consumer Research, 1-4.

Misita, Caron P. (2013), "Clinical Pharmacists in Outpatient Diabetes Care: Essential Members of the Multidisciplinary Team," Clinical Diabetes, 31 (4), 162-65.

Monge, Peter R. and Noshir S. Contractor (2003), Theories of Communication Networks. New York: Oxford University Press.

Needham, Catherine (2007), "Citizen-Consumers: Changing Publics and Changing Public Services," Sociology of Health \& Illness, 58 (4), 719-21.

Oliver, Daniel G., Julianne M. Serovich, and Tina L. Mason (2005), "Constraints and Opportunities with Interview Transcription: Towards Reflection in Qualitative Research," Social Forces, 84 (2), 1273-89.

Peerson, Anita and Margo Saunders (2009), "Health Literacy Revisited: What Do We Mean and Why Does It Matter?" Health Promotion International, 24 (3), 285-96.

Prigge, Jana-Kristin, Beatrix Dietz, Christian Homburg, Wayne D. Hoyer, and Jennifer L. Burton (2015), "Patient Empowerment: A Cross-Disease Exploration of Antecedents and Consequences," International Journal of Research in Marketing, 32 (4), 375-86.
Rubenstein, Ellen L. (2012), “'Things My Doctor Never Told Me': Bridging Information Gaps in an Online Community," Proceedings of the American Society for Information Science and Technology, 49 (1), 1-10.

Santos, Nicholas J.C., Gene R. Laczniak, and Tina M. Facca-Miess (2015), "The 'Integrative Justice Model' as Transformative Justice for Base-of-the-Pyramid Marketing," Journal of Business Ethics, 126 (4), 697-707.

Schembri, Sharon (2006), "Rationalizing Service Logic, or Understanding Services as Experience?" Marketing Theory, 6 (3), 381-92.

Singaraju, Stephen P., Quan Anh Nguyen, Outi Niininen, and Gillian Sullivan-Mort (2016), "Social Media and Value Co-Creation in Multi-Stakeholder Systems: A Resource Integration Approach," Industrial Marketing Management, 54 (April), 44-55.

Singh, Jagdip and Deepak Sirdeshmukh (2000), "Agency and Trust Mechanisms in Consumer Satisfaction and Loyalty Judgements," Journal of the Academy of Marketing Science, 28 (1), 150-67.

Spanjol, Jelena, Anna S. Cui, Cheryl Nakata, Lisa K. Sharp, Stephanie Y. Crawford, Yazhen Xiao, et al. (2015), "Co-Production of Prolonged, Complex, and Negative Services: An Examination of Medication Adherence in Chronically Ill Individuals," Journal of Service Research, 18 (3), 284-302.

Stange, Kurt C. (2009), "The Problem of Fragmentation and the Need for Integrative Solutions," Annals of Family Medicine, 7 (2), $100-03$.

Stewart, David W. (2015), "Why Marketers Should Study Public Policy," Journal of Public Policy \& Marketing, 34 (1), 1-3.

Thom, David H., Danielle Hessler, Rachel Willard-Grace, Thomas Bodenheimer, Adriana Najmabadi, Christina Araujo, et al. (2014), "Does Health Coaching Change Patients' Trust in Their Primary Care Provider?" Patient Education and Counseling, 96 (1), 135-38.

Thompson, Craig J. (1997), "Interpreting Consumers: A Hermeneutical Framework for Deriving Marketing Insights from the Texts of Consumers' Consumption Stories," Journal of Marketing Research, 34 (November), 438-55.

Thorsen, Dag Einar (2010), "The Neoliberal Challenge: What Is Neoliberalism?" Contemporary Readings in Law and Social Justice, 2 (2), 188-214.

Tost, Leigh Plunkett (2011), "An Integrative Model of Legitimacy Judgments," Academy of Management Review, 36 (4), 686-710.

Townsend, Anne, Jenny Leese, Paul Adam, Michael McDonald, Linda C. Li, Sheila Kerr, et al. (2015), "EHealth, Participatory Medicine, and Ethical Care: A Focus Group Study of Patients' and Health Care Providers' Use of Health-Related Internet Information," Journal of Medical Internet Research, 17 (6), e155.

Vargo, Stephen L. and Robert F. Lusch (2008), "Service-Dominant Logic: Continuing the Evolution," Journal of the Academy of Marketing Science, 36 (1), 1-10.

and - (2012), Toward a Better Understanding of the Role of Value in Markets and Marketing. Bingley, UK: Emerald Group.

Versel, Neil (2016), “Apple's New CareKit Helps Design of SelfCare Apps," MedCity News, (March 21), [available at http:// medcitynews.com/2016/03/apple-carekit/].

Ward, Vicky and Simon Smith, Allan House, and Susan Hamer (2012), "Exploring Knowledge Exchange: A Useful Framework 
for Practice and Policy," Social Science \& Medicine, 74 (3), 297-304.

Wiest, Amber L., David L. Andrews, and Michael D. Giardina (2015), "Training the Body for Healthism: Reifying Vitality in and Through the Clinical Gaze of the Neoliberal Fitness Club," Review of Education, Pedagogy \& Cultural Studies, 37 (1), 21-40.

Williams, Toni (2007), "Empowerment of Whom and for What? Financial Literacy Education and the New Regulation of Consumer Financial Services," Law \& Policy, 29 (2), 226-56.
Yngfalk, Carl and Anna Fyrberg Yngfalk (2015), "Creating the Cautious Consumer Marketing Managerialism and Bio-Power in Health Consumption," Journal of Macromarketing, 35 (4), 435-47.

Zarcadoolas, Christina, Andrew Pleasant, and David S. Greer (2009), Advancing Health Literacy: A Framework for Understanding and Action. San Francisco: John Wiley \& Sons.

Zwick, Detlev, Samuel K. Bonsu, and Aron Darmody (2008), "Putting Consumers to Work: 'Co-Creation' and New Marketing Govern-Mentality," Journal of Consumer Culture, 8 (2), 163-96. 


\section{AUTHOR QUERIES}

\section{AUTHOR PLEASE ANSWER ALL QUERIES}

Q: 1_AUTHOR: Do you have an e-mail affiliated with your university? We would prefer it over a gmail address. 